\title{
SOSIALISASI PEMBUATAN MEREK PRODUK UKM DI KELURAHAN PEDURUNGAN SEMARANG
}

\author{
Oleh: \\ Emaya Kurniawati ${ }^{1}$, Sri Yuni Widowati, Aprih Santoso \\ 1) Fakultas Ekonomi Universitas Semarang \\ Email : aprihsantoso@usm.ac.id
}

\begin{abstract}
The Community Service Program that we will carry out is located at RT $14 R \mathrm{R} 09$ Pedurungan Tengah Village with the target audience of UKM in the RT! 4 RW 09 area. Pedurungan Tengah Village, Semarang. These SMEs produce food products whose sales are increasing day by day and have a wider range of consumers. Products that have been sold in the market and are well known do not yet have a name or brand, SMEs do not understand the importance of a brand for a product. They only care about the important product sold. In this Community Service activity to introduce more about the importance of a brand for a product, socialization and an explanation of the importance of the name or product brand are given to differentiate it from other similar products.

From the results of this dedication, it is hoped that participants will be able to understand the importance of brands for products that have been produced and make them start thinking about or designing names or brands for their products.
\end{abstract}

Key words: product, brands, SMEs, sales

\section{PENDAHULUAN}

Saat ini, di era perdagangan global baik di dalam maupun di luar negeri persaingan bisnisnya semakin meningkat ketat. Menurut Kotler (2005) dalam Samboro, et. al (2019) menyebutkan pemasaran adalah suatu proses sosial dan manajerial dengan mana perseorangan atau kelompok memperoleh apa yang mereka butuhkan dan inginkan melalui pembuatan, pertukaran produk yang bernilai bagi pihak lain. Dalam pemasaran terdapat suatu kegiatan atas produk yang dihasilkan suatu usaha yaitu berupa pemvberian merek. Pengertian merek sebagai bagian dari Hak Milik Intelektual tidak terlepas dari pemahaman bahwa hak merek diawali dari temuan-temuan dalam bidang Hak Kekayaan Intelektual lainnya, misalnya hak cipta (Sulastri, et. al, 2018). Sejak ratusan tahun mereke telah dipakai guna memberikan ciri pada produk yang telah dihasilkan dengan tujuan untuk menunjukkan asal usul barang (indication of origin). Merek adalah alat pembeda produk dan juga sebagai petunjuk kualitas suatu produk selain itu juga sebagai pengenal atau identitas yang akan memudahkan konsumen untuk memutuskan pilihannya membeli atau tidak membeli. Jika produk tidak mempunyai merek, maka otomatis tidak akan dikenal atau dibutuhkan konsumen, oleh karena itu suatu produk apakah produk itu baik atau tidak, pasti akan memakai merek tertentu. Merek berpengaruh terhadap Keputusan Pembelian Konsumen pada Produk Makanan di UMKM (Mulyadi, 2015). Hal ini sejalan dengan Kusmawati \& Samboro (2015) yang menyatakan bahwa disamping faktor psikologis ternyata faktor ekuitas merek juga berpengaruh terhadap keputusan pembelian. Oleh karena itu, merek suatu produk berperan penting untuk menunjang suatu usaha.

Pengabdian kepada Masyarakat yang berlokasi RT 14 RW 09 Kelurahan Peduru ngan Tengah Semarang, dengan kalayak sasaran UKM di wilayah RT 14 RW 09 Kelurahan Pedurungan Tengah, yang mana dalam wilayah tersebut terdapat beberapa 
usaha yang produknya dihasilkan oleh ibuibu rumah tangga yang berkeinganan untuk menambah penghasilan keluarga terutama pada masa pandemi Covid 19 sekarang ini sehingga dapat meningkatklan kesejahteraan keluarga. Salah satu hasil produknya adalah makanan yaitu Lunpia, peyek kacang, peyek teri dan Roti Bolen. Penjualannya ditawar kan melalui teman atau saudara untuk dijual kembali.

Selanjutnya, pelaku usaha juga perlu diberikan penyuluhan mengenai pentingnya pemberian merek pada produk yang dimiliki, karena selain sebagai tanda pembeda, merek juga memiliki fungsi penting sebagai hak kepemilikan agar merek yang dimiliki terhindar dari penjiplakan/peniruan oleh pelaku usaha lain. Fungsi inilah yang belum diketahui oleh pelaku usaha sebagai legaitas merek, karena berdasarkan pemahaman pelaku usaha merek hanya sekedar tanda pembeda saja. Menurut Wijayanti, et. al (2020) menyatakan bahwa beberapa pelaku usaha menempatkan merek produk yang telah mereka pilih namun belum dicantumkan pada kemasan sehingga tidak memiliki keunggulan untuk bersaing di pasaran.

Saat ini, UMKM merupakan porsi terbesar dari kegiatan perekonomian masyarakat. Meskipun merupakan penyela mat ekonomi nasional, UMKM memiliki masalah yang menghambat pertumbuhannya (Sudarwati \& Satya, 2013).

Pengabdian kepada Masyarakat yang akan dilaksanakan fokus pada pelaku usaha UKM di RT 14 RW 09 Kelurahan Pedu rungan Tengah Semarang sebagai target program dengan tujuan agar pelaku usaha UMK mendapatkan pemahaman mengenai pentingnya merek bagi suatu produk sebagai sehingga pemahaman tersebut dapat diterapkan dalam kegiatan usaha serta dapat memperbaiki kualitas usaha yang sedang dijalankan. Sampai sekarang UKM di RT 14 RW 09 Kelurahan Pedurungan Tengah menghadapi masalah uyaitu belum memaha mi tentang pentingnya merek untuk suatu produk terutama untuk produk yang ada pesaingnya atau bukan produk tunggal.

\section{KAJIAN LITERATUR}

\subsection{Ruang Lingkup UMKM}

Departemen Perindustrian dan

Perdagangan mendefinisikan dapat dikatakan
UMKM jika memiliki kriteria sebagai berikut : 1. Perusahaan memiliki aset maksimal $\mathrm{Rp}$ 600 juta di luar tanah dan bangunan 2 . Perusahaan memiliki modal kerja di bawah Rp 25 juta f. Departemen Keuangan: UMKM adalah perusahaan yang memiliki omset maksimal Rp 600 juta per tahun dan atau aset maksimum $\mathrm{Rp} 600$ juta di luar tanah dan bangunan.

Dalam Undang - undang No.20 Tahun 2008, pengertian usaha digolongkan sebagai berikut (Juliprijanto, et. al (2017): 1. Usaha Mikro adalah usaha produktif milik orang perorangan dan/atau badan usaha perorangan yang memenuhi kriteria Usaha Mikro sebagaimana diatur dalam Undang - undang ini. 2. Usaha Kecil adalah usaha ekonomi produktif yang berdiri sendiri, yang dilakukan oleh orang perorangan atau badan usaha yang bukan merupakan anak perusahaan atau bukan cabang perusahaan yang dimiliki, dikuasai, atau menjadi bagian baik langsung maupun tidak langsung dari Usaha Menengah atau Usaha Besar yang memenuhi kriteria Usaha Kecil sebagaimana dimaksud dalam Undang-Undang ini. 3. Usaha Menengah adalah usaha ekonomi produktif yang berdiri sendiri, yang dilakukan oleh orang pero rangan atau badan usaha yang bukan merupakan anak perusahaan atau cabang perusahaan yang dimiliki, dikuasai, atau menjadi bagian baik langsung maupun tidak langsung dengan Usaha Kecil atau Usaha Besar dengan jumlah kekayaan bersih atau hasil penjualan tahunan sebagaimana diatur dalam UndangUndang ini.

Badan Pusat Statistik Nasional (BPS) BPS memberikan definisi UMKM berdasar kan kuantitas tenaga kerja. Usaha kecil merupakan entitas usaha yang memiliki jumlah tenaga kerja 5 s.d. 19 orang, sedang kan usaha menengah merupakan entitias usaha yang memiliki tenaga kerja 20 s.d. 99 orang. Karakteristik UMKM menurut Bank Indonesia (BI) adalah perusahaan atau industry sebagai berikut: 1 . Modalnya kurang dari Rp. 20 juta. 2. Untuk satu putaran dari usahanya hanya membutuhkan dana $\mathrm{Rp} 5$ juta. 3. Memiliki aset maksimum Rp 600 juta di luar tanah dan bangunan. 4. Omzet tahunan $\leq \mathrm{Rp} 1$ miliar.

Undang-Undang Nomor 20 Tahun 2008 tentang Usaha Mikro, Kecil dan Menengah (UMKM) : Pengertian UMKM 1. Usaha 
Mikro adalah usaha produktif milik orang perorangan atau badan usaha perorangan yang memenuhi kriteria Usaha Mikro sebagaimana diatur dalam UndangUndang. 2. Usaha Kecil adalah usaha ekonomi produktif yang berdiri sendiri, yang dilakukan oleh orang perorangan atau badan usaha yang bukan merupakan anak perusahaan atau bukan cabang perusahaan yang dimiliki, dikuasai, atau menjadi bagian baik langsung maupun tidak langsung dari usaha menengah atau usaha besar yang memenuhi kriteria Usaha Kecil sebagaimana dimaksud dalam Undangundang ini. 3. Usaha Menengah adalah usaha ekonomi produktif yang berdiri sendiri, yang dilakukan oleh orang perseorangan atau badan usaha yang bukan merupakan anak perusahaan atau cabang perusahaan yang dimiliki, dikuasai, atau menjadi bagian baik langsung maupun tidak langsung dengan usaha kecil atau usaha besar dengan jumlah kekayaan bersih atau hasil penjualan tahunan sebagaimana diatur dalam Undang-Undang ini.

Departemen Koperasi dan Usaha Kecil Menengah (UU No. 9 Tahun 1995), yang dimaksud dengan Usaha Kecil (UK), termasuk Usaha Mikro (UMI) adalah entitas usaha yang mempunyai memiliki kekayaan bersih paling banyak Rp 200.000.000,- tidak termasuk tanah dan bangunan tempat usaha, dan memiliki penjualan tahunan paling banyak Rp 1.000.000.000,- .

Sementara itu, Usaha Menengah (UM) merupakan entitas usaha milik warga negara Indonesia dengan kekayaan bersih antara $\mathrm{Rp}$ 200.000.000 s.d. Rp10.000.000.000,- tidak termasuk tanah dan bangunan. Menurut Trisnawati (2016) menyatakan bahwa UKM juga dapat dikelompokan atas klasifikasi pra usaha, usaha berjalan dan usaha maju.

\subsection{Ruang Lingkup Merek}

Undang-undang Nomor 15 tahun 2001 tentang Merek yang selanjtutnya disebut Undang-Undang Merek merupakan penyempurnaan dari Undang-Undang Nomor 19 tahun 1992 dan Undang-Undang Nomor 14 tahun 1997. Indonesia telah memiliki suatu perlindungan hukum yang sah dan jelas terhadap Hak Milik Intelektual terutama dalam bidang Merek. Undang-undang merek menganut sistem konstitutif, yang artinya hak atas merek timbul karena adanya pendaftaran, Seseorang atau badan hukum yang ingin memperoleh hak atas merek diwajibkan untuk mengajukan permintaan pendaftaran kepada Direktorat Jenderal Hak Kekayaan Intelektual (Dirjen HaKI) terlebih dahulu. Hak atas merek diatur dalam Pasal 3 Undang-Undang Merek yang berbunyi, "Hak Atas Merek adalah hak eksklusif yang diberikan oleh negara kepada pemilik merek yang terdaftar dalam daftar umum merek dalam jangka waktu tertentu dengan menggunakan sendiri merek tersebut atau memberikan ijin kepada pihak lain untuk menggunakannya (Anonim, 2005).

Merek mempunyai fungsi untuk memberi tanda pengenal barang, guna membedakan barang seseorang atau perusahaan dengan barang orang atau perusahaan lain. Disamping itu ada tujuantujuan lain dilihat dari pihak produsen, pedagang dan konsumen. Dari pihak produsen, merek digunakan untuk jaminan nilai hasil produksi, khususnya mengenai kualitas, kemudahan pemakaiannya atau halhal yang pada umumnya berkenaan dengan teknologinya. Bagi pedagang, merek digunakan untuk mempromosikan barangbarang dagangannya guna mencari meluaskan pasaran.

Dari pihak konsumen, merek diperlukan untuk mengadakan pilihan terhadap barang yang akan dibeli (Miru, 2005). Menurut Wardhani \& Samboro ( ) menyatakan bahwa banyak upaya yang dilakukan oleh perusahaan untuk menciptakan citra merek (brand image) yang baik di mata konsumen. Menurut Ranto (2014) menyatakan bahwa pengalaman konsumen baik secara langsung atau tidak langsung dalam berhubungan dengan merek baik penyedia jasa atau produk akan mempengaruhi citra dari penyedia tersebut.

\section{METODE}

Metode pelaksanaan dalam kegiatan $\mathrm{PkM}$ ini memberikan sosialisasi melalui ceramah, diskusi dan tanya jawab serta simulasi. Metode pendekatan yang digunakan dalam kegiatan ini adalah: memberikan penjelasan tentang apa itu merek dan gunanya merek bagi suatu produk dan memberikan penjelasan tentang bagaimana mengelola suatu usaha dengan baik dan benar sehingga usahanya tetap bertahan dan semakin berkembang. 


\section{HASIL DAN PEMBAHASAN \\ 4.1Proses Pelaksanaan Kegiatan}

Pelaksanaan kegiatan Pengabdian kepada Masyarakat yang dilaksanakan pada masa pandemi Covid 19 ini dilaksanakan dengan batasan personil dan mematuhi protokol kesehatan. Dalam pelaksanaannya memanfaatkan waktu pelaksanaan dengan efisien dan efektif sehingga hasil yang diharapkan dapat tercapai. Tahap-tahap dalam pelaksanaan kegiatan pengabdian sebagai berikut :

1. Melakukan survey lokasi yang menjadi obyek pengabdian yaitu UKM RT 14 RW 09 Kelurahan Pedurungan Tengah Semarang dan melakukan wawancara awal dengan pelaku UKM tentang pelaksanaan kegiatan pengabdian yang akan dilaksanakan.

2. Pelaksanaan pengabdian dilaksanakan pada Hari Selasa tanggal 15 Desember 2020.

\subsection{Materi Penyuluhan}

Pengetahuan dan Teknologi bukan saja bermanfaat bagi masyarakat biasa akan tetapi juga sangat bermanfaat bagi masyarakat yang bergerak di bidang usaha (Rulirianto, et. al. 2020). Menurut Adriansyah \& Sudiarto, 2019) menyatakan bahwa pengembangan UMKM tidak terlepas dengan peranan pemasaran dalam kelangsungan hidup usaha. Pada awal kegiatan yaitu selain memberikan penjelasan tentang penting suatu nama atau merek bagi produk.

Adapun materi penyuluhan yaitu:

1.Pertama tama yang dijelaskan oleh tim arti suatu nama atau merek bagi suatu produk sehingga pruduk lebih dikenal karena orang akan membeli pasti menyebutkan nama atau merek produk yang akan dibeli

2.Tim mencoba mengusulan utk memberi nama atau merek khususnya utk produk lumpia, peyek dan juga Roti Bolen. Untuk lunpia akan dineri sudah disepakai seuai dengan nam panggilan pembuat lumpia yaitu mbak londho, maka produk lumpia tersebut muncul ide Lunpia "Ny Londho", dengan harapan akan membuat penasaran pembeli dengan kata Londho, sedangkan untuk peyek teri diberi nama peyek teri "Arull" renyah dan gurih. dan untuk roti Bolen diberi nama Roti Bolen "Della"
Rencana design dan nama produk lunpia dan peyek :

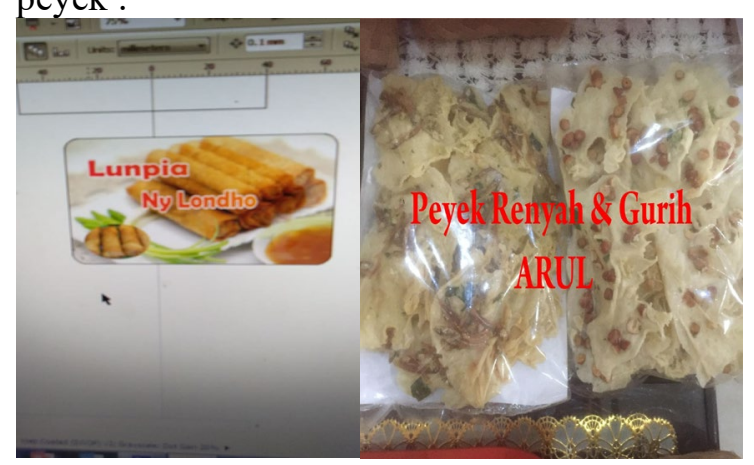

Dokumentasi kegiatan dan Contoh produk yang dihasilkan:
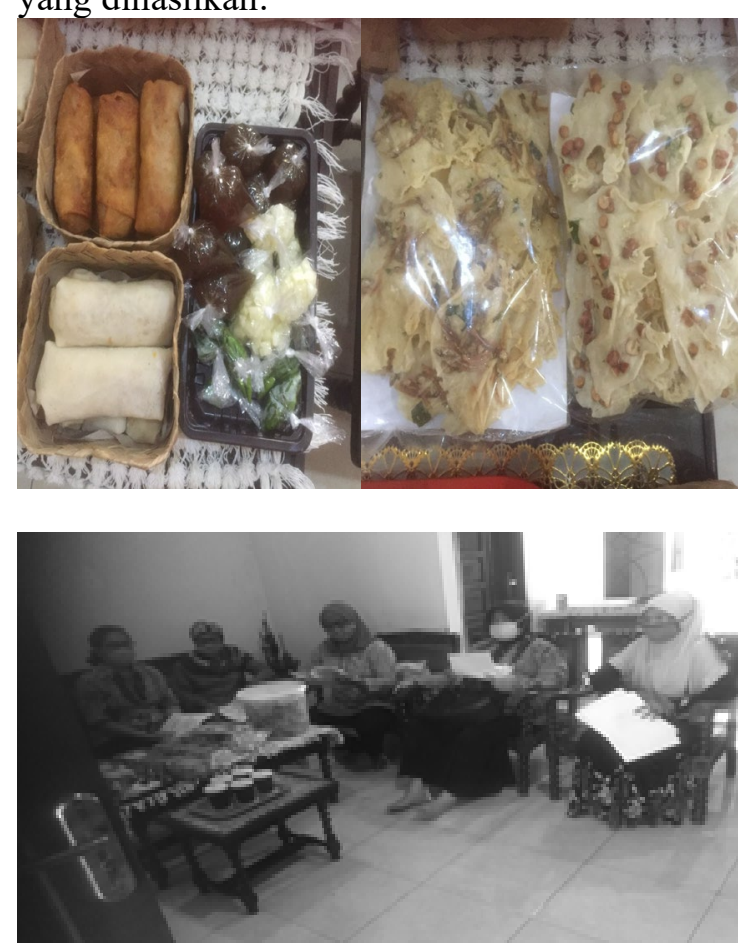

\section{Luaran Yang Dicapai}

Luaran yang dicapai dari kegiatan pengabdian adalah jurnal pengabdian dan peningkatan Iptek di masyarakat melalui penyuluhan dan sosialisasi tentang penting nya merek produk sehingga produk yang dihasilkan dapat dikenal oleh konsumen.

\section{SIMPULAN}

Sosialisasi tentang pentingnya merek produk sangat diminati oleh peserta yang mana ditunjukkan dengan antuasiasnya peserta ingin memberi nama pada produk yang sudah dihasilkan sehingga produk yang dijualnya akan lebih dikenal oleh masyarakat atau konsumen. Berdasarkan dari hasil sosialisasi tenatng pentingnya merek produk 
sudah ada beberapa ide tentang nama untuk produk yang akan dijual, misalanya untuk : Lunpia, diberi nama Lunpia "Ny. Londo", untuk Peyek diberi nama peyek "AUREL" renyah dan gurih dan untuk roti bolen akan diberi nama Roti Bolen "DELLA". Setelah mengikuti pengabdian ini pemilik produk Lunpia, Peyek dan Roti Bolen akan menjual produknya dengan nama atau merek ini.

Atas dasar hal tersebut maka diberikan saran yaitu UKM RT 14 RW 09 Kelurahan Pedurungan Tengah Semarang diharapkan segera membuat dan menempelkan nama atau merek bagi produk-produknya dengan nama yang sudah disepakati atau sudah dipertimbangkan sehingga produknya akan lebih cepat dikenal

\section{DAFTAR REFERENSI}

Adriansyah, A. \& Sudiarto, E. 2019. PKM Pe ngusaha Tahu Desa Sumberejo Wetan Kecamatan Ngunut Kabupaten Tulung agung. J-ABDIMAS. 6(2), 95-100

Anonim, 2005. Indonesia, Departemen Hukum dan Hak Asasi Manusia, Direktorat Jenderal Hak Kekayaan Intelektual, Buku Panduan : Hak Kekayaan Intelektual.

Juliprijanto, W., Sarfiah, S.N., Priyono, N. 2017. Diskripsi Dan Permasalahan Pelaku Usaha Kecil Menengah (UKM) (Studi Kasus UKM di Desa Balesari, Kecamatan Windusari). Jurnal Riset Ekonomi Pembangunan. 2(2), 77-90

Kotler, Philip. 2005. Manajemen Pemasaran. Jilid 1 dan 2. Jakarta : PT Indeks Kelompok Gramedia

Kusmawati, E. \& Samboro, J. 2015. Pengaruh Faktor Psikologis Dan Ekuitas Merek Terhadap Keputusan Pembelian Produk Tupperware (Studi Pada Warga Desa Tlekung Kota Batu). JAB : Jurnal Aplikasi Bisnis. 1(1), 91-100

Miru, Ahmadi. 2005. Hukum Merek : Cara Mudah Mempelajari Undang-undang Merek, Jakarta: PT. Raja Grafindo Persada.

Mulyadi, Gugun. 2015. Pengaruh Merek Dan Kemasan Terhadap Keputusan Pembelian Produk UMKM. Ekonologi : Jurnal Ilmu Manajemen. 2(1), 105-109

Ranto, D.W.P. 2014. Pengaruh Harga, Desain Produk, Kualitas Produk Dan Citra
Merek Terhadap Keputusan Pembelian Konsumen Pada Produk Ukm Di Yogyakarta. Jurnal Bisnis : Teori dan Implementasi, 5(2), 206-218

Rulirianto, Febriyanti, A.P, Hidayatinnisa, N., Kusumasasti, I. 2020. Bimbingan Dan Pelatihan Kelompok Aneka Usaha Kemitraan Perorangan Ukm Di Bhaskara Ds. Kalisari Kec.Mulyorejo Surabaya Jawa Timur. J-ABDIMAS. 7(1), 84-91.

Samboro, J., Helmy, A., Zubaidi, Widodo, T.W., Rulirianto. 2019. Bimbingan Dan Pelatihan Tentang Pentingnya Kualitas Pelayanan Dan Toko Online Bagi Pengembangan Usaha Garmen “AMAR" Di Malang. J-ABDIMAS. 6(1), 33-38

Sudarwati, Y., Satya, V.E. 2013. Strategi Pengembangan Merek Usaha Mikro, Kecil, Dan Menengah (Microfinance, Small, and Medium Enterprises Branding Strategy). Jurnal Ekonomi \& Kebijakan Publik. 4(1), 89 - 101

Sulastri, Satino, Yuli, Y.W. 2018. Perlindungan Hukum Terhadap Merek (Tinjauan Terhadap Merek Dagang Tupperware Versus Tulipware). Jurnal Yuridis. 5(1), 160-172.

Trisnawati, 2016. Kajian Inovasi Sektor Usaha Kecil Menengah (UKM) dengan Pendekatan Sistem Dinamis (Studi Kasus pada Industri Makanan di Kabupaten Sidoarjo Jawa Timur). Jurnal Akuntansi, Ekonomi dan Manajemen Bisnis. 4(1), 60-67

Undang-undang Nomor 20 Tahun 2008 tentang usaha Milro, Kredit dan Menengah

Wardhani, P.A.K. \& Samboro, J. 2016. Pengaruh Citra Merek (Brand Image) Dan Kualitas Produk Terhadap Keputusan Pembelian Sepatu Merek Nike (Studi Pada Mahasiswa Jurusan Administrasi Niaga Politeknik Negeri Malang Tahun Akademik 2015-2016). JAB :Jurnal Aplikasi Bisnis. 2(1), 45-48 Wijayanti, R.F., Budiarti, L., Andi. E.S., Dwi. J.P, Trivena, S.M. 2020. Bimbingan Dan Pelatihan Desain Label Kemasan Pada Ukm Kerupuk Di Desa Ampeldento Karangploso. J-ABDIMAS. 7(1), 69-76 
